\title{
The Effects of Different Extraction Methods on Antioxidant Properties, Chemical Composition, and Thermal Behavior of Black Seed (Nigella sativa L.) Oil
}

\author{
Nameer Khairullah Mohammed, ${ }^{1,2}$ Mohd Yazid Abd Manap, ${ }^{1,3}$ Chin Ping Tan, \\ Belal J. Muhialdin, ${ }^{1}$ Amaal M. Alhelli, ${ }^{1}$ and Anis Shobirin Meor Hussin ${ }^{1,3}$ \\ ${ }^{1}$ Faculty of Food Science and Technology, Universiti Putra Malaysia (UPM), 43400 Serdang, Selangor, Malaysia \\ ${ }^{2}$ Department of Food Science and Biotechnology, College of Agriculture, University of Tikrit, Tikrit, Iraq \\ ${ }^{3}$ Halal Products Research Institute, Universiti Putra Malaysia (UPM), 43400 Serdang, Malaysia \\ Correspondence should be addressed to Anis Shobirin Meor Hussin; anisshobirin@gmail.com
}

Received 8 June 2016; Revised 22 July 2016; Accepted 25 July 2016

Academic Editor: Yoshiji Ohta

Copyright @ 2016 Nameer Khairullah Mohammed et al. This is an open access article distributed under the Creative Commons Attribution License, which permits unrestricted use, distribution, and reproduction in any medium, provided the original work is properly cited.

\begin{abstract}
The Nigella sativa L. popularly referred to as black seeds are widely used as a form of traditional nutrition and medicine. N. sativa seeds were used for the extraction of their oil by way of supercritical fluid extraction (SFE) and cold press (CP) to determine the physicochemical properties, antioxidant activity, and thermal behavior. The GC-MS results showed the primary constituents in the Nigella sativa oil (NSO) were Caryophyllene (17.47\%) followed by thymoquinone (TQ) (11.80\%), 1,4-Cyclohexadiene (7.17\%), longifolene $(3.5 \%)$, and carvacrol $(1.82 \%)$. The concentration of TQ was found to be $6.63 \mathrm{mg} / \mathrm{mL}$ for oil extracted using SFE and $1.56 \mathrm{mg} / \mathrm{mL}$ for oil extracted by CP method. The antioxidant activity measured by DPPH and the $\mathrm{IC}_{50}$ was $1.58 \mathrm{mg} / \mathrm{mL}$ and $2.30 \mathrm{mg} / \mathrm{mL}$ for SFE oil and cold pressed oil, respectively. The ferric reducing/antioxidant power (FRAP) activity for SFE oil and CP oil was $538.67 \mathrm{mmol} / 100 \mathrm{~mL}$ and $329.00 \mathrm{mmol} / 100 \mathrm{~mL}$, respectively. The total phenolic content (TPC) of SFE oil was $160.51 \mathrm{mg} / 100 \mathrm{~mL}$ and $94.40 \mathrm{mg} / 100 \mathrm{~mL}$ for $\mathrm{CP}$ oil presented as gallic acid equivalents (GAE). This research showed that a high level of natural antioxidants could be derived from NSO extracted by SFE.
\end{abstract}

\section{Introduction}

Black seed (Nigella sativa L.), traditionally used to treat fever, headache, anxiety, diarrhea, asthma, and stroke, is known to be highly anti-inflammatory $[1,2]$. N. sativa seed is rich in phenolic compounds used as an antioxidant agent [1] and in essential fatty acids besides bioactive compounds such as sterols and tocols [3]. Moreover, the yellowish oil contains proteins, amino acids, reducing sugars, mucilage, alkaloids, organic acids, tannins, resins, toxic glucoside, metarbin, bitter principles, glycosidal saponins, crude fiber, minerals, and vitamins [4]. Among the various oil seeds, N. sativa oil (NSO) is particularly interesting as it may be utilized in preparations that contain phytochemicals with strong antioxidant properties and health benefits $[5,6]$. Thymoquinone (TQ) is an active compound in the crude extracts of NSO, which possesses antioxidant/anti-inflammatory efficacy in models of in vitro and in vivo investigations as well as asthma, diabetes, encephalomyelitis, neurodegeneration, and carcinogenesis $[5,7]$.

Methods of extraction of seed oils are an effective factor in the properties of oils. Solvent extraction, for example, is deficient in selectivity and needs extreme heat, which could cause the degradation of the desired components [8]. The cold press extraction is the conventional method for oil extraction. It involves no heat and/or chemicals and this is preferred by consumers concerned about natural and safe food [9]. However, this method affords low yields [10], and the residual meal contains $10-12 \%$ oil content, which can eventually limit its uses in industries processing food [11]. Supercritical fluid extraction (SFE) is currently a technique among others used to extract plant oils and offers some favorable features over the 
traditional techniques that have been used in the oil industry [12]. In general, SFE has been the recommended method used to extract antioxidant compounds from NSO and exhibits a higher concentration of thymoquinone [13].

This study aims to compare the properties of NSO extracted using SFE and cold press with regard to the antioxidant activity, chemical composition, TQ concentration, and the thermal behavior of the oil.

\section{Experimental}

2.1. Materials and Methods. N. sativa seeds were sourced from the Serdang spice market in West Malaysia. Analyticalgrade solvents, thymoquinone (99.9\% purity) and 1,1diphenyl-picryl-hydrazyl, came from Sigma-Aldrich (St. Louis, MO, USA).

2.2. Chemical Properties of Nigella sativa L. Seeds. Moisture (930.04), ash (930.05), and protein (978.04) contents were established based on [17]. Fat determination was done using Soxhlet extractor and hexane as the solvent. In brief, $15 \mathrm{~g}$ of seed were ground and fat was obtained after $8 \mathrm{~h}$ of extraction and the results were presented as the amount in percent of lipids in the dry matter of seed powder, while estimation of the carbohydrate content achieved was expressed in terms of the variance of the mean values, that is,

$$
[100-(\text { protein }+ \text { lipids }+ \text { ash }+ \text { moisture })] .
$$

\subsection{Oil Extraction}

2.3.1. Cold Pressing. The N. sativa L. seeds were pressed at room temperature $\left(25^{\circ} \mathrm{C}\right)$ by mechanical pressing without any heating treatment. Crushed seeds were stored for one night at room temperature to separate oil phase from fibers, and then oil was filtered using Watman \#4 filter paper and a glass funnel.

2.3.2. Supercritical Fluid Extraction. Extracting essential oil from $N$. sativa L. seed was performed using the SFE instrument (FeyeCon Development B. V., Netherland) at the supercritical fluid centre, Faculty of Food Science and Technology, UPM, as described by [18], with some modification. The dried seeds were completely crushed for 3-4 min in a stainless steel grinder (Waring Commercial, Torrington, CT, USA) and kept in a 50-liter extractor container of the same material and tightly sealed. Supercritical fluid extractions were conducted at pressures of 600 bar and temperatures of $40^{\circ} \mathrm{C}$ for the duration of $1 \mathrm{~h}$, and liquid $\mathrm{CO}_{2}$ was injected at approximately $150 \mathrm{~L} /$ hour and controlled by an automatic back pressure regulator.

2.4. Physicochemical Properties of Nigella sativa Oil. Peroxide value (PV), free fatty acids content (FFA), saponification value (SV), and iodine value (IV) were established based on [17]. The refractive index (RI) was calculated with Abbe Refractometer at $20^{\circ} \mathrm{C}$. The viscosity of NSO was extracted using SFE and cold press was recorded at $25^{\circ} \mathrm{C}$ with a Haake
Rheometer (model Stress 600, Thermo Electron Corporation, Karlsruhe, Germany). The rheometer is, in essence, a dynamically managed stress instrument with a standard sensor system and a plate (PP35Ti). Data received were subjected to analysis with Haake RheoWin 3 Data Manager software. The steel cone-plate (C40/4) measuring system was utilized to measure how viscous the samples were at a shear rate of 0 to $100 \mathrm{~s}^{-1}$. All measurements were carried out in triplicate.

2.5. GC-MS Test. GC-MS analyses were conducted in a gas chromatograph Trace GC Ultra gas chromatograph attached to a TSQ Quantum XLS triple quadruple mass spectrometer, both from Thermo Scientific (Waltham, MA, USA). All the analyses were performed with a fused silica DB-5-MS column $(30 \mathrm{~m} \times 0.25 \mathrm{~mm} \times 0.25 \mu \mathrm{m})$, which was employed for all the analyses. The temperature of the oven was raised to $220^{\circ} \mathrm{C}$ from $70^{\circ} \mathrm{C}$ at $4^{\circ} \mathrm{C} / \mathrm{min}$ and maintained isothermally for $15 \mathrm{~min}$. The temperatures of the injector and detector temperatures were maintained at $220^{\circ} \mathrm{C}$ and $240^{\circ} \mathrm{C}$, respectively, with the preparation of $10 \%$ of samples in acetonitrile. The split mode ratio of $1: 15$ was applied for the injection of a $0.5 \mu \mathrm{L}$ sample. Carrier gas used was helium at $1 \mathrm{~mL} / \mathrm{min}$ flow rate. Other parameters were kept the same in relation to $\mathrm{GC}$ analyses. EI at $70 \mathrm{eV}$ provided the mass spectra with mass scanning done from 40 to $400 \mathrm{amu}$. Percentage of each component was calculated based on GC peak areas.

2.6. HPLC Quantification of Thymoquinone. Thymoquinone evaluation of NSO was conducted along the lines of the approach taken by [19] with minor modification. The oils obtained from SFE and cold press extraction methods were passed through a C18 column preeluted with methanol. $20 \mu \mathrm{L}$ of NSO followed by $800 \mu \mathrm{L}(400 \mu \mathrm{L} \times 2)$ methanol was added to give an eluate free from greasy and fatty materials. The analysis was carried out on the oils from SFE and cold press extraction methods for TQ with the use of Agilent 1200 HPLC system (Agilent Technologies, Palo Alto, USA) with a diode array detector (HPLC-DAD). A Prevail C18 column $(250 \times 4.6 \mathrm{~mm}$ ID, with $5 \mu \mathrm{m}$ particle size, Agilent Technologies, USA) was employed with a mobile phase of water : methanol : 2-propanol (50: $45: 5 \% \mathrm{v} / \mathrm{v})$ which was filtered using a $0.45 \mathrm{~mm}$ Millipore filter and $20 \mu \mathrm{L}$ was the volume of the injection. Analysis of thymoquinone was detected at $254 \mathrm{~nm}$ at room temperature. A $1.5 \mathrm{~mL} / \mathrm{min}$ flow rate was used and identification was confirmed through a comparison of the time, the standard compound was retained with that of oil sample and the quantity calculations were achieved by constructing the standard linear calibration curves.

\subsection{1, 1-Diphenyl-2-picrylhydrazyl (DPPH) Radical Scaveng-} ing Activity Test. This assay was performed according to [20] with some changes made to establish the radical scavenging activity of NSO. The DPPH solution was prepared fresh as and when it was needed by diluting $2.5 \mathrm{mg} \mathrm{DPPH}$ in $100 \mathrm{~mL}$ methanol. Then, the mixture of $0.25 \mathrm{~mL}$ of NSO and $1.75 \mathrm{~mL}$ methanolic DPPH was prepared in a 96-wall plate. Following $30 \mathrm{~min}$ of incubation in the dark and at ambient 
temperature $\left(25^{\circ} \mathrm{C}\right)$, the absorbance was measured at $515 \mathrm{~nm}$, the wave length of highest absorbance of DPPH was noted with an ELISA reader (labomed, model UVD-2950, USA). A blank experiment or control was done applying similar steps to a solution minus the test material. The absorbance was recorded as $A$. The free radical scavenging activity of all solutions was then calculated as percentage of inhibition on the basis of the following equation:

$$
\% \text { inhibition }=\frac{(A-B)}{A} * 100 \text {, }
$$

where $A=$ absorbance of control and $B=$ absorbance of the sample.

Antioxidant activities of test compounds were expressed as $\mathrm{IC}_{50}$, which is represented by the amount of antioxidant compounds that caused $50 \%$ scavenging of DPPH radicals for the duration of the defined time frame.

2.8. FRAP Assay. The ability of the NSO antioxidant of the ferric reducing power was assessed with (FRAP) assay as indicated by [21]. Briefly, FRAP reagent was freshly prepared, and $20 \mathrm{mM} \mathrm{FeC}_{l 3}$ and $10 \mathrm{mM}$ TPTZ solutions were mixed in $40 \mathrm{mM} \mathrm{HCl}$ and $300 \mathrm{mM}$ acetate buffer $(\mathrm{pH}$ 3.6) in ratios of $1: 1: 10(\mathrm{v} / \mathrm{v} / \mathrm{v})$. Then, $10 \mu \mathrm{L}$ of sample (dissolved $100 \mu \mathrm{g}$ in $1 \mathrm{~mL}$ methanol) was distributed into a 96-well plate, and then $200 \mu \mathrm{L}$ of FRAP reagent was placed into the same well containing the sample. The solution was mixed and incubated for $30 \mathrm{~min}$ at room temperature. The absorbance was recorded at $593 \mathrm{~nm}$ using ELISA reader (Power Wave $\times 340$, BioTek Instruments, Inc., Winooski, VT, USA). Results of FRAP were expressed in $\mathrm{mM}$ of ferrous equivalents, Fe (II) per $g$ three times and readings were taken in triplicate.

2.9. Total Phenolic Content. The entire amount of phenolic compounds (TPC) of NSO was established with the use of Folin-Ciocalteu reagent (FCR) according to [22] with certain changes. There was the addition of $0.5 \mathrm{~mL}$ sample to $0.5 \mathrm{~mL}$ of Folin-Ciocalteu reagent, and 5 minutes later, $10 \mathrm{~mL}$ of $7 \%$ of aqueous $\mathrm{Na}_{2} \mathrm{CO}_{3}$ sodium carbonate solution was added and mixed to react then kept for 1 hour in total darkness at room temperature. The absorbance was read at $725 \mathrm{~nm}$ employing ELISA reader (Power Wave $\times 340$, BioTek Instruments, Inc., Winooski, VT, USA). A standard curve of gallic acid was separately made from versus concentration $(0-1 \mathrm{mg} / \mathrm{mL})$. The outcomes were presented in gallic acid equivalents (GAE) $\mathrm{mg} / \mathrm{kg}$ dry weight. All experiments were conducted three times and reading was obtained in triplicate.

2.10. FTIR Spectroscopy. Fourier-transform infrared (FTIR) spectroscopy of NSO extracted by either SFE or cold press machine was carried out on a Spectrum 100 FTIR spectrometer from Perkin-Elmer Corporation, USA. FTIR for the samples was recorded over the range of $400-4000 \mathrm{~cm}^{-1}$ employing a sample of approximately one percent in $200 \mathrm{mg}$ of spectroscopic-grade potassium bromide ( $\mathrm{KBr}$ ) with 10 tons of pressure.
2.11. Thermal Behavior DSC. Thermal properties of NSO extracted by SFE and cold press were examined by differential scanning calorimeter using DSC 820e from Mettler Toledo (Schwerzenbach, Switzerland). Weighing of the oil samples was done (8-9 mg) straight into a DSC-pan (SFI-Aluminium, TA Instrument T11024). An empty aluminium pan, hermetically sealed, was the reference. The samples were heated from $30^{\circ} \mathrm{C}$ with a speed of $5^{\circ} \mathrm{C} / \mathrm{min}$ to $90^{\circ} \mathrm{C}$. The same process was repeated and recording of the DSC thermographs was done during the second melting. The DSC manufacturer's software (STARe Speciality Library) was employed to analyse the data of the heat flow and the exact heat of the oil samples was calculated. Results were derived by averaging triplicate samples.

2.12. Thermogravimetric Analysis (TGA). Thermogravimetric method determines the thermal properties of oils as a function of temperature. Examination of the thermally induced degradation of the oils was conducted in a thermogravimetric analysis (TGA) Perkin-Elmer Thermogravimetry Analyzer Pyris 2. The analysis was carried out on approximately $25 \mathrm{mg}$ of samples at the temperature range of 25$1000^{\circ} \mathrm{C}$ at a constant heating rate of $25^{\circ} \mathrm{C} / \mathrm{min}$ in an atmosphere of nitrogen.

2.13. Statistical Analysis. The considerable variance of the mean values was confirmed using Tukey's test. A probability of $p>0.05$ was deemed significant. The statistical software, MINITAB 16 (Minitab Inc., State College, PA, USA) was employed for all the analyses.

\section{Results}

3.1. Physicochemical Properties of Nigella sativa L. Seed. The approximated structure of the $N$. sativa seed powder and related literature references are presented in Table 1 . The analysis of the N. sativa L. seed demonstrated its contents to be $32.37 \%$ lipids, $6.78 \%$ moisture, $19.23 \%$ protein, $6.94 \%$ ash, and $35.08 \%$ carbohydrate. FFA values of NSO extracted by SFE and CP methods were significantly different with values of 6.15 and $5.98 \%$ (as oleic acid), respectively (Table 2). The iodine values were $115 \mathrm{~g}$ of I2/100 $\mathrm{g}$ of oil for SFE and $104 \mathrm{~g}$ of I2/100 $\mathrm{g}$ of oil for CP oil (Table 2). The SFE and CP extracted oils showed the saponification values of $243.52(\mathrm{mg}$ of $\mathrm{KOH} / \mathrm{g}$ of oil) and 238.26 (mg of $\mathrm{KOH} / \mathrm{g}$ of oil), respectively (Table 2). Table 2 presents the refractive index (RI) of NSO extracted by SFE and cold press 1.47813 and 1.47719, respectively. Peroxide values (PV) of oils obtained by using SFE and cold pressing extraction were 3.4 and 4.1 meq $\mathrm{O}_{2} / \mathrm{kg}$ oil, respectively.

3.2. GC-MS Studies. The results showed significant differences between the SFE and the cold press oils based on the peak area (Table 3 ). Twenty compounds were identified in the SFE oil, while the cold press oil had 19 compounds. The major components of the SFE oil were Caryophyllene $(17.47 \%)$ followed by thymoquinone (16.80\%), 1,4-Cyclohexadiene (7.17\%), longifolene (3.5), and carvacrol (1.82\%) (Figure 1(a)). 
TABLE 1: Chemical properties of the selected Nigella sativa seed in comparison with previous studies.

\begin{tabular}{lccccc}
\hline Total fat & Moisture & Ash & Protein & Carbohydrate & Studies \\
\hline $32.26 \pm 0.09$ & $6.67 \pm 0.20$ & $6.82 \pm 0.10$ & $19.19 \pm 0.20$ & $35.04 \pm 0.30$ & Current study \\
$31.72 \pm 0.42$ & $4.99 \pm 0.29$ & $5.29 \pm 0.41$ & $23.07 \pm 1.05$ & $34.91 \pm 1.22$ & Solati et al., 2014 [13] \\
$40.35 \pm 0.16$ & - & $4.41 \pm 0.01$ & $22.6 \pm 0.24$ & $32.7 \pm 0.41$ & Cheikh-Rouhou et al., 2007 [14] \\
$34.8 \pm 1.90$ & $7.0 \pm 0.50$ & $3.7 \pm 0.70$ & $20.8 \pm 1.10$ & $33.7 \pm 0.50$ & Atta, 2003 [15] \\
$37.33 \pm 0.15$ & $5.40 \pm 0.13$ & $6.72 \pm 0.02$ & $20.02 \pm 0.27$ & 30.53 & Khoddami et al., 2011 [16] \\
\hline
\end{tabular}

TABLE 2: Oil physiochemical properties obtained using two extraction methods.

\begin{tabular}{lcc}
\hline $\begin{array}{l}\text { Physiochemical } \\
\text { properties }\end{array}$ & $\begin{array}{c}\text { Supercritical fluid } \\
\text { extraction }\end{array}$ & $\begin{array}{c}\text { Cold press } \\
\text { extraction }\end{array}$ \\
\hline FFA (as oleic \%) & $5.98 \pm 0.00^{\mathrm{b}}$ & $6.15 \pm 0.00^{\mathrm{a}}$ \\
SV (mg of KOH/g of & $243.52 \pm 0.3^{\mathrm{a}}$ & $238.26 \pm 0.67^{\mathrm{b}}$ \\
oil) & $115.1 \pm 0.24^{\mathrm{a}}$ & $104.37 \pm 0.43^{\mathrm{b}}$ \\
$\mathrm{IV}\left(\mathrm{g}\right.$ of $\mathrm{I}_{2} / 100$ g of oil) & $3.4 \pm 0.05^{\mathrm{a}}$ & $4.1 \pm 0.15^{\mathrm{b}}$ \\
PV (meq $\mathrm{O}_{2} / \mathrm{kg}$ oil) & $1.47 \pm 0.00^{\mathrm{a}}$ & $1.47 \pm 0.00^{\mathrm{a}}$ \\
Refractive index at & \\
$\left(25^{\circ} \mathrm{C}\right)$ & $6.26 \pm 0.07^{\mathrm{a}}$ & $6.38 \pm 0.08^{\mathrm{a}}$ \\
\hline Viscosity (mPa s)
\end{tabular}

Means of triplicate measurements in the same row \pm standard deviation with different letters are significantly different $(p<0.05)$.

The major components for cold press oil were 1,3,8-pMenthatriene (23.82\%) followed by thymoquinone (16.21\%), 1,4-Cyclohexadiene (7.17\%), longifolene (4.49), and carvacrol (3.90\%) (Figure 1(b)).

The HPLC analysis showed that the two oil samples (SFE and cold pressed) contained thymoquinone TQ (Figures 2(a) and 2(b)). The highest amount of TQ was observed in the SFE oil and was $6.63 \mathrm{mg} / \mathrm{mL}$ of oil, while the concentration of TQ was $1.56 \mathrm{mg} / \mathrm{mL}$ oil for the cold press sample (Table 4$)$. The methods of extraction showed important differences $(p>$ $0.05)$ for the SFE with higher thymoquinone quantity.

3.3. Antioxidant Activity of Nigella sativa L. Oil. The antiradical activity of NSO to scavenge DPPH demonstrated high levels with SFE oil $\mathrm{IC}_{50}$ being $1.5873 \mathrm{mg} / \mathrm{mL}$ while the $\mathrm{CP}$ oil $\mathrm{IC}_{50}$ was $2.3086 \mathrm{mg} / \mathrm{mL}$ (Table 5). The reducing ability of NSO extracted by two methods, SFE and cold press, was in the range of $329.00-538.67 \mathrm{~mol} / 100 \mathrm{~mL}$ oil (Table 5). The concentration of overall phenolic compounds (TPC) in NSO extracted by SFE and CP was assessed using Folin-Ciocalteu method presented as gallic acid equivalents as can be seen in Table 5. Results in this table show a considerable difference $(p<0.05)$ between the overall phenolic content of the SFE oil with a value of $160.51 \mathrm{mg}$ GAE/100 $\mathrm{mL}$ and CP oil with a value of $94.40 \mathrm{mg} \mathrm{GAE} / 100 \mathrm{~mL}$ (Table 5).

3.4. FTIR Spectra of Nigella sativa L. Oil. Figure 3 reveals FTIR spectrum of SFE and CP oils at mid infrared region $\left(4,000-650 \mathrm{~cm}^{-1}\right)$. In this study, the spectrum of both oils showed very close features of absorption bands identical to the most common triglyceride molecules with certain fatty acids (Table 6).

3.5. Thermal Behavior of Nigella sativa L. Oil. These curves of the SFE and CP oils showed a plain thermogram with one peak possessing features such as onset temperature at $203.66^{\circ} \mathrm{C}$ and $243.03^{\circ} \mathrm{C}$, melting enthalpy is $30.48 \mathrm{~J} / \mathrm{g}$ and $34.50 \mathrm{~J} / \mathrm{g}$, and melting peak $241.04^{\circ} \mathrm{C}$ and $264.35^{\circ} \mathrm{C}$, respectively (Figures 4(a) and 4(b)).

The weight loss occurred in SFE oil in the percentage of 35.1 and $63.4 \%$ at 208 and $365^{\circ} \mathrm{C}$, respectively (Figures 5(a) and 5(b)). TGA and DTG curves for the SFE oil showed the degradation in two steps, first point at $308.5^{\circ} \mathrm{C}$ and second degradation at $365.5^{\circ} \mathrm{C}$, while for the $\mathrm{CP}$ oil had weight loss of 6.3 and $91.4 \%$ at 212.4 and $33.3^{\circ} \mathrm{C}$, respectively. In addition, degradation points have been observed in CP oil at $288.3^{\circ} \mathrm{C}$ and $423.77^{\circ} \mathrm{C}$, respectively.

\section{Discussion}

The analysis of the $N$. sativa $L$. seed demonstrated that its contents of lipids and moisture were in the range of those found in the literature, while protein was slightly lower and ash with carbohydrate (by difference) were higher compared to those revealed in the literature [13-16]. The chemical properties of oils are considered the most significant feature to determine the quality of oil samples.

In this work, chemically, the properties of $N$. sativa L. oil extracted using SFE and cold press were studied. Free fatty acid and peroxide value are the commonly used indicators to monitor the quality of seed oils. In the current study, the low FFA value demonstrated that oil extracted with the SFE method had higher stability than that obtained by CP extraction. This finding is in agreement with the oil obtained through SFE method (5.83\%) and Soxhlet method $(6.40 \%)$ in [13] and much less compared to cold pressed oil (11\%) [14]. In another study, the iodine value was higher than that of this study's results according to [23] for SFE oil (127 $\mathrm{g}$ of $\mathrm{I}_{2} / 100 \mathrm{~g}$ of oil) and (121 $\mathrm{g}$ of $\mathrm{I}_{2} / 100 \mathrm{~g}$ of oil) for Soxhlet oil. The iodine index shows that NSO is an extremely unsaturated oil, suggesting that it possesses elevated levels of oleic and linoleic acids, with the lower iodine value contributing to the high stability of the oil [14]. The saponification values (SV) of NSO extracted by SFE and CP methods were high compared to other seed oils suggesting the presence of high triacylglycerols content. The saponification values in this study were comparable to the values of Tunisian 211 (mg of $\mathrm{KOH} / \mathrm{g}$ of oil) and Iranian 218 (mg of $\mathrm{KOH} / \mathrm{g}$ of oil) 
TABLE 3: GC-MS identification of chemical composition for Nigella sativa oil extracted by supercritical fluid and cold press.

\begin{tabular}{|c|c|c|c|c|c|c|c|}
\hline & \multirow{2}{*}{ Compound name } & \multicolumn{3}{|c|}{ Supercritical fluid } & \multicolumn{3}{|c|}{ Cold press } \\
\hline & & MW & $\mathrm{RT}$ & Peak area (\%) & MW & $\mathrm{RT}$ & Peak area (\%) \\
\hline 1 & $\alpha$-Pinene & - & - & - & 136 & 3.19 & 7.10 \\
\hline 2 & 3-Carene & 136 & 3.29 & 2.60 & 136 & 3.29 & 2.21 \\
\hline 3 & Bicyclo[2.2.1]heptane & 136 & 4.00 & 2.05 & 136 & 4.00 & 3.67 \\
\hline 4 & 1,3,8-p-Menthatriene & - & - & - & 134 & 4.96 & 23.82 \\
\hline 5 & ç-Terpinene & - & - & - & 136 & 5.64 & 2.82 \\
\hline 6 & 1,4-Cyclohexadiene & 134 & 5.01 & 7.17 & - & - & - \\
\hline 7 & cis-4-Methoxy thujane & 168 & 6.45 & 3.09 & 168 & 7.05 & 7.30 \\
\hline 8 & Cyclohexen & 154 & 8.90 & 3.82 & - & - & - \\
\hline 9 & Limonene & - & - & - & 236 & 8.41 & 0.41 \\
\hline 10 & Thymoquinone & 164 & 11.32 & 16.80 & 164 & 11.06 & 16.21 \\
\hline 11 & Carvacrol & 150 & 13.51 & 1.82 & 150 & 13.46 & 3.90 \\
\hline 12 & Longifolene & 204 & 13.70 & 3.50 & 204 & 15.37 & 4.49 \\
\hline 13 & Ylangene & 204 & 14.50 & 2.99 & 204 & 13.67 & 0.82 \\
\hline 14 & 3-Allyl-6-methoxyphenol & 164 & 14.61 & 0.40 & - & - & - \\
\hline 15 & 1-Heptatriacotanol & - & - & - & 536 & 20.91 & 0.14 \\
\hline 16 & 2,3-Dihydrofarnesyl acetate & - & - & - & 266 & 30.91 & 1.54 \\
\hline 17 & Caryophyllene & 204 & 16.03 & 17.45 & - & - & - \\
\hline 18 & Naphthalene & 204 & 17.88 & 2.94 & - & - & - \\
\hline 19 & $\alpha$-Bisabolene & 204 & 18.50 & 0.50 & - & - & - \\
\hline 20 & (-)-Spathulenol & 220 & 22.37 & 0.79 & - & - & - \\
\hline 21 & Methyl tetradecanoate & 242 & 24.54 & 0.54 & - & - & - \\
\hline 22 & Hexadecanoic acid & 254 & 29.69 & 4.99 & 254 & 31.65 & 0.77 \\
\hline 23 & Ascorbic acid & 652 & 31.75 & 1.12 & 652 & 34.95 & 2.15 \\
\hline 24 & 9,12-Octadecadienoic acid $(\mathrm{Z}, \mathrm{Z})$ & 294 & 33.70 & 14.05 & 294 & 35.45 & 7.85 \\
\hline 25 & 4,8-Decadienal, 5,9-dimethyl & - & - & - & 180 & 33.84 & 8.12 \\
\hline 26 & Methyl stearate & 298 & 34.34 & 0.61 & & & \\
\hline 27 & Butyl 9,12-octadecadienoate & 336 & 35.11 & 2.29 & 336 & 11.77 & 0.21 \\
\hline 28 & Cyclopropanebutanoic acid & - & - & - & 374 & 37.66 & 0.25 \\
\hline & Total & & & 89.54 & & & 93.53 \\
\hline
\end{tabular}

MW: molecular weight.

RT: retention time.

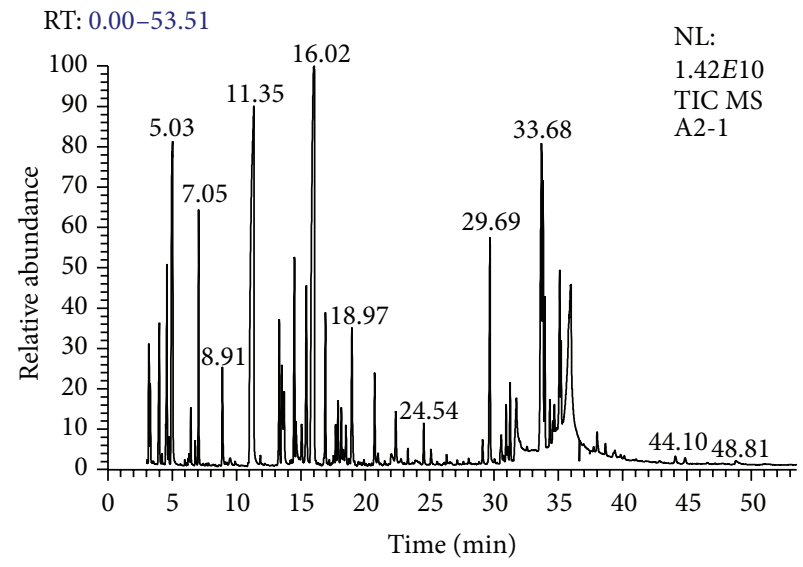

(a)

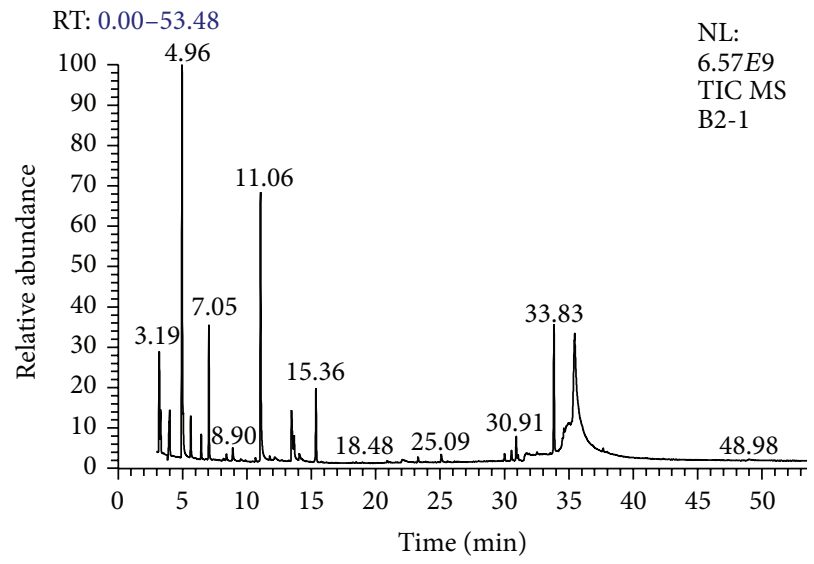

(b)

FIGURE 1: GC-MS chromatography analysis of Nigella sativa oil extracted by (a) 474 supercritical fluid and (b) cold press. 


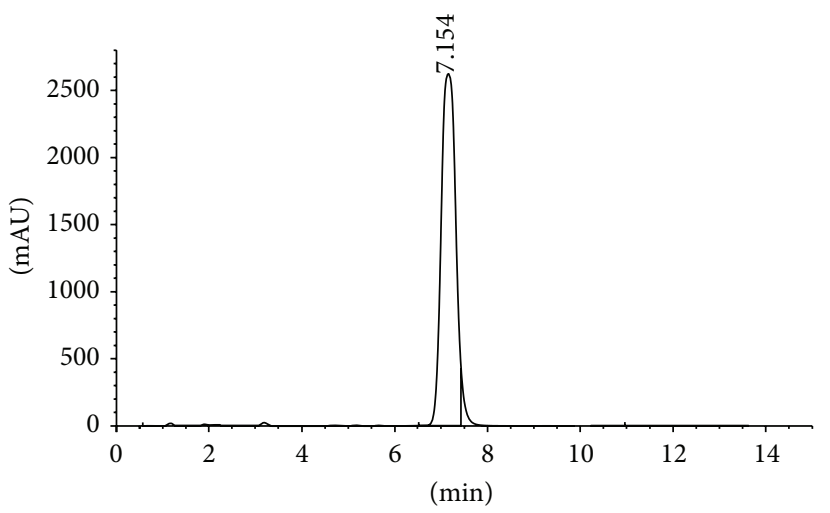

(a)

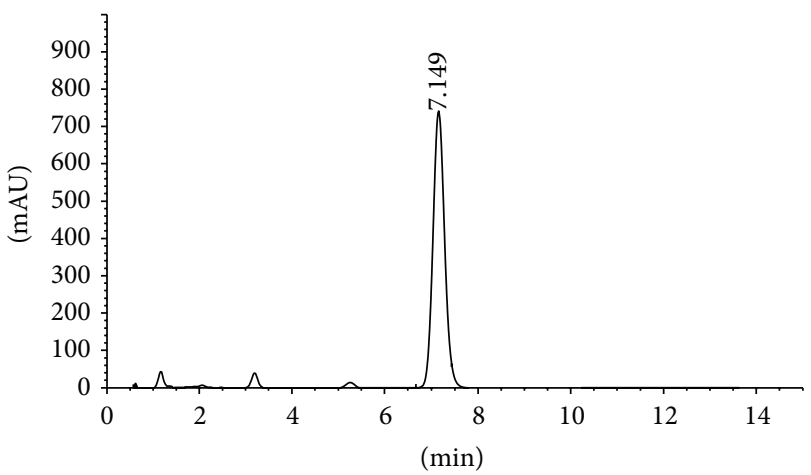

(b)

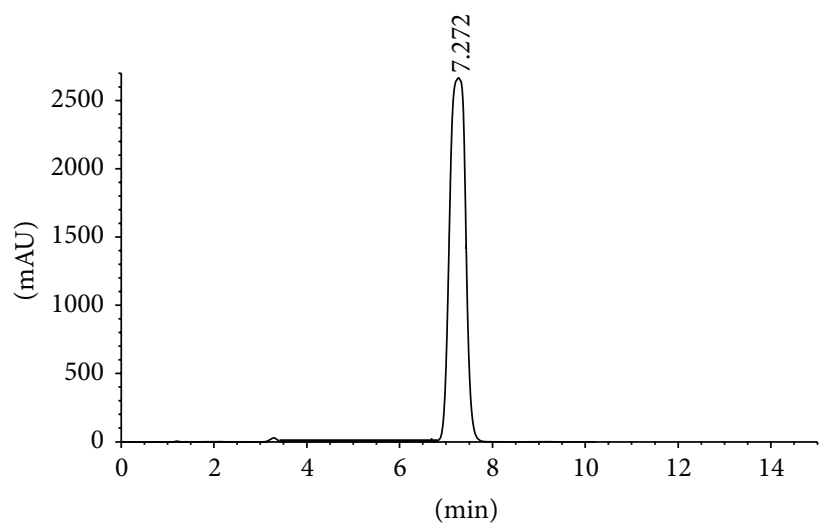

(c)

FIGURE 2: Thymoquinone concentration of Nigella sativa oil as determined by HPLC: (a) 490 supercritical fluid extraction, (b) cold press extraction, and (c) thymoquinone standard.

TABLE 4: Thymoquinone concentration of Nigella sativa oil extracted by supercritical fluid and cold press as determined by HPLC.

\begin{tabular}{lc}
\hline Extraction methods & Thymoquinone \\
\hline SFE oil & $6.37 \pm 0.00^{\mathrm{a}} \mathrm{mg} / \mathrm{mL}$ \\
CP oil & $1.78 \pm 0.00^{\mathrm{b}} \mathrm{mg} / \mathrm{mL}$ \\
\hline
\end{tabular}

\pm Standard deviation of three replications.

${ }^{\mathrm{ab}}$ Different letters in the same column represent significant $(p<0.05)$ differences.

extract from CP extraction with hexane reported by [14]. The result of refractive index (RI) was similar to those reported previously, while the peroxide values (PV) of oils were lower than cold press $13.5 \mathrm{meq} \mathrm{O}_{2} / \mathrm{kg}$ oil reported by [15]. There could be a relation between these differences and the dissimilarities of cultivated regions, maturity stage, and storage circumstances. According to the data reported about the nutritional value of $N$. sativa seed, it is noted that besides the high oil content it is also a rich source of many minerals and bioactive compounds. Compounds were recognized through comparison of their retention indices and mass obtained in GC-MS chromatogram (Figures 1(a) and 1(b)) with those of NIST02 library data stored in the computer library and Adams libraries spectra [24, 25] and enumerated along with molecular weight, retention time, and

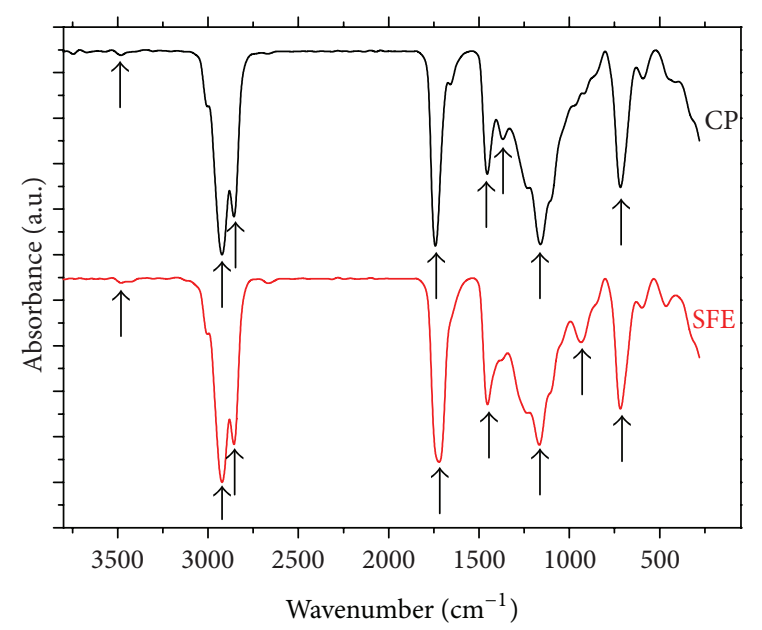

FIGURE 3: FTIR spectra of Nigella sativa L. oil scanned at 4,000$650 \mathrm{~cm}^{-1}$ : supercritical fluid (SFE) and cold press (CP).

peak area. Burits and Bucar's [1] method for the extraction of essential oil used light petroleum followed by steam distilling of the extract. They indicated that their essential oil possessed thymoquinone as the main component, while in this study 
TABLE 5: Antioxidant activities of Nigella sativa oil determined by DPPH radical scavenging and FRAP ferrous reducing, with TPC total phenolic content.

\begin{tabular}{lccc}
\hline Types of oil & DPPH IC $_{50}(\mathrm{mg} / \mathrm{mL})$ & FRAP $(\mathrm{mmol} / 100 \mathrm{~mL})$ & TPC $(\mathrm{mg} / 100 \mathrm{~mL}$ GAE $)$ \\
\hline Supercritical fluid oil & $1.58 \pm 0.07^{\mathrm{b}}$ & $538.67 \pm 12.58^{\mathrm{a}}$ & $160.51 \pm 11.43^{\mathrm{a}}$ \\
Cold press oil & $2.30 \pm 0.02^{\mathrm{a}}$ & $329.00 \pm 54.78^{\mathrm{b}}$ & $94.40 \pm 1.02^{\mathrm{b}}$ \\
\hline
\end{tabular}

\pm Standard deviation of three replications.

${ }^{\mathrm{ab}}$ Different letters in the same column represent significant $(p<0.05)$ differences.

TABLE 6: The main peaks in the FTIR spectrum of Nigella sativa oils extracted by supercritical fluid of and cold press with their assignment.

\begin{tabular}{lcc}
\hline Oil types & Peak $\left(\mathrm{cm}^{-1}\right)$ & Functional group \\
\hline SFE-CP & 3482 & Primary amines $\left(-\mathrm{NH}_{2}\right.$ groups $)$ \\
SFE-CP & 2922,2856 & $\mathrm{C}-\mathrm{H}$ stretching vibration $($ aliphatic $)\left(\mathrm{CH}_{3}\right)$ \\
SFE-CP & 1721 & $\mathrm{C}=\mathrm{O}_{\text {stretching vibration }(\mathrm{ester})}$ \\
SFE-CP & $1456,1367.74$ & $\mathrm{C}-\mathrm{H}$ bending vibration $(\mathrm{aliph}$ betic $)\left(\mathrm{CH}_{2}\right)$ \\
SFE-CP & 1166.48 & $\mathrm{C}-\mathrm{O}$ stretching vibration $(\mathrm{ester})$ \\
SFE-CP & $935.42,717.35$ & trans- $\mathrm{CH}=\mathrm{CH}-$ \\
\hline
\end{tabular}

Caryophyllene is the major component of the SFE oil and 1,3,8-p-Menthatriene for cold press oil.

The high content of thymoquinone could be because of the greater selectivity of the SFE method compared to cold press. Generally, extractions using cold press result in partial oil recovery [26]. In fact, the cold press gives low yields, and usually the extraction process is time consuming [10] which may affect the concentration of the target compounds from NSO quantity. The results for thymoquinone quantity were similar to those of Solati et al. [13] who reported that the NSO extracted by SFE had a high content of TQ with $4.09 \mathrm{mg} / \mathrm{mL}$. Furthermore, Ismail et al. [18] reported that NSO extracted with SFE was rich in thymoquinone with the percentage of about four times higher compared to the oil extracted by conventional solvent extraction method. TQ is a phytochemical compound of NSO, which is interesting for study as it contributes to the oil's general stability and potential health benefits [27]. It has also been shown to be the reason for the biological antioxidant activity of NSO and also for the majority of the beneficial health effects related to the seeds and oils [13].

The antiradical activity of NSO to scavenge DPPH was determined based on their $\mathrm{IC}_{50}$ values, described as the quantum of the antioxidant needed to inhibit $50 \%$ of DPPH existing in the test material. Both the SFE and CP oils had high ability to decrease the stable radical DPPH. The earlier studies by $[1,13]$ reported higher $\mathrm{IC}_{50}$ (lowest antioxidant activity) compared to this study's $\mathrm{IC}_{50}$ of $2.26 \mathrm{mg} / \mathrm{mL}$. These data confirm that SFE is a more appropriate method of extraction for NSO. The SFE oil exhibited a high antioxidant power corresponding to that of $\mathrm{CP}$ oil. The ferric reducing ability (FRAP assay) is very often employed to evaluate the antioxidant component in dietary polyphenols [28]. Antioxidant activity is known to have a linear proportion of the phenolic contents. Oktay et al. [29] mentioned the likelihood of total phenolic contents and antioxidant activity being very positively related between, a trend that seems to be prevalent in several species of plants. Sielicka and Samotyja [30] evaluated several oils for ferric reducing activity, and among the tested oils, the highest activity was observed for NSO, which ranged between 678 and $2102 \mu \mathrm{mol} / 100 \mathrm{~g}$ oil. Compared to this study, the results are significantly higher for both CP oil and SFE oil. The SFE oil exhibited the highest FRAP activity which indicated the advantages of the SFE method.

Polyphenolic compounds are acknowledged to be antioxidant active and there is a likelihood that these compounds are the cause of abstracts activity [31]. In other studies, total phenolic contents of NSO extracted by solvent from Tunisian and Iranian Nigella sativa seeds were 245 and $309 \mathrm{mg} / \mathrm{kg}$ expressed as gallic acid, respectively [14]. Viuda-Martos et al. [32] determined the TPC in NSO and observed the high content of phenolic compounds $(726.67 \mathrm{mg} / \mathrm{L})$ in the commercial oil, and these results mirror those of $\mathrm{CP}$ oil in this study, while these findings were much less than the oil extracted by SFE. This indicates that using SFE for the extraction of the oil is preferred as it will yield a higher concentration of phenolic compounds.

Differential scanning calorimetry DSC offers evidence of the additional specific heat across a broad temperature range [33]. Any endothermic or exothermic event is noted as a peak in the chart, and its area is in proportion to the enthalpy achieved or lost, respectively. Figures 4(a) and 4(b) show the DSC melting curves for NSO extracted by two different extraction methods. The melting curves of these seed oils show more endothermic peaks and shoulders. In general, both NSO samples showed similar DSC melting point and profiles higher than $200^{\circ} \mathrm{C}$ temperature regions. This result concurs with published data [14]. Thermogravimetric analysis (TGA) and derivative thermograms analysis (DTG) were conducted to determine the thermal stability of two samples for NSO extracted by SFE and cold press. Thermogravimetric analysis (TGA), also referred to as thermogravimetry (TG), is a technique where measuring the thermal behavior of mass 


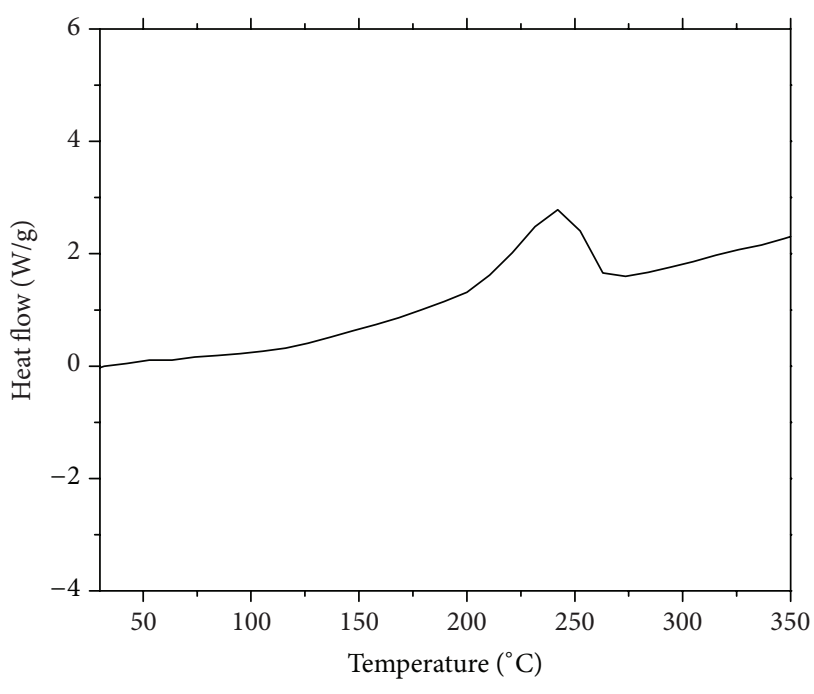

- SFE

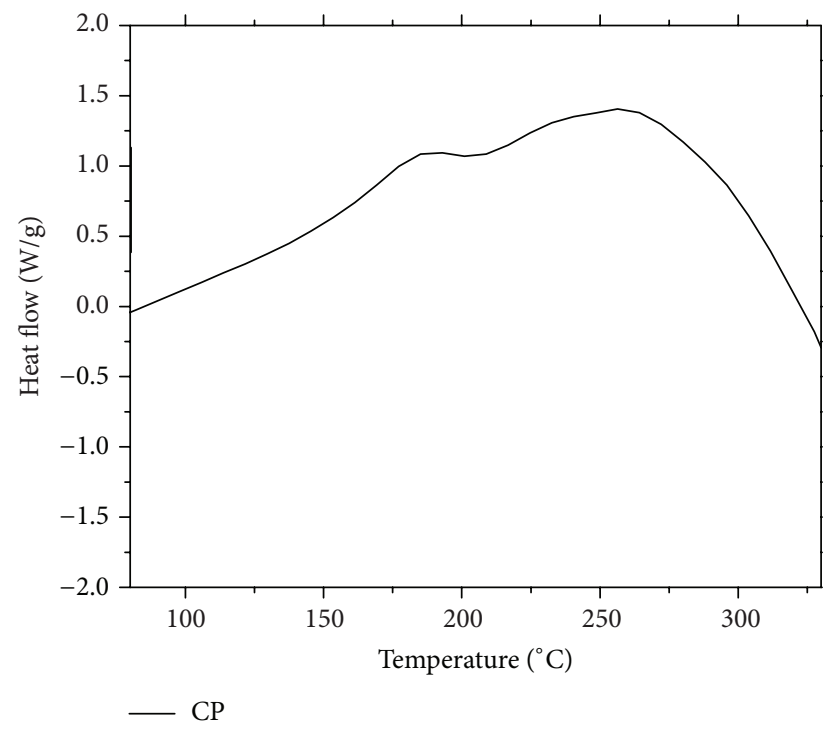

(b)

FIGURE 4: Differential scanning calorimetry (DSC) thermal behavior of Nigella sativa oil: 529 (a) supercritical fluid and (b) cold press.

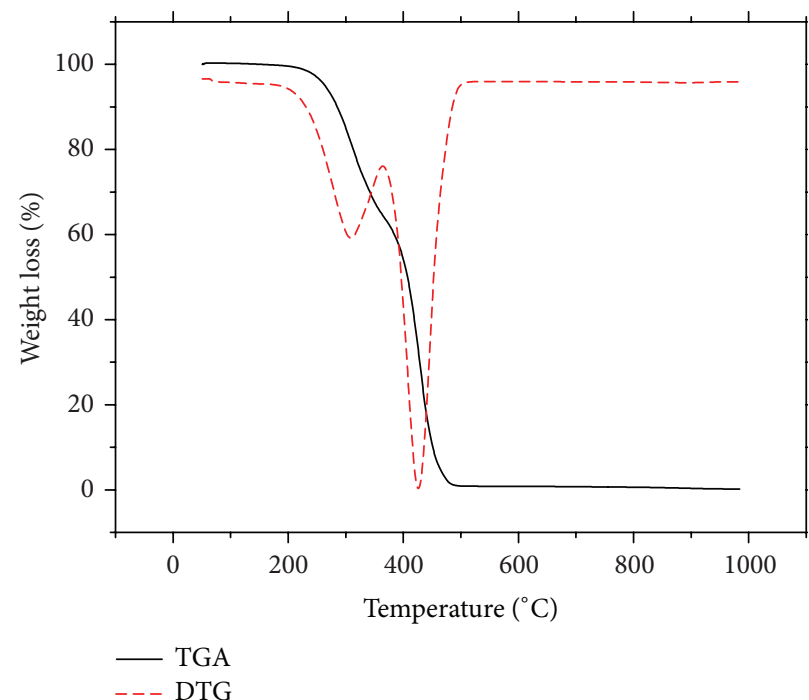

(a)

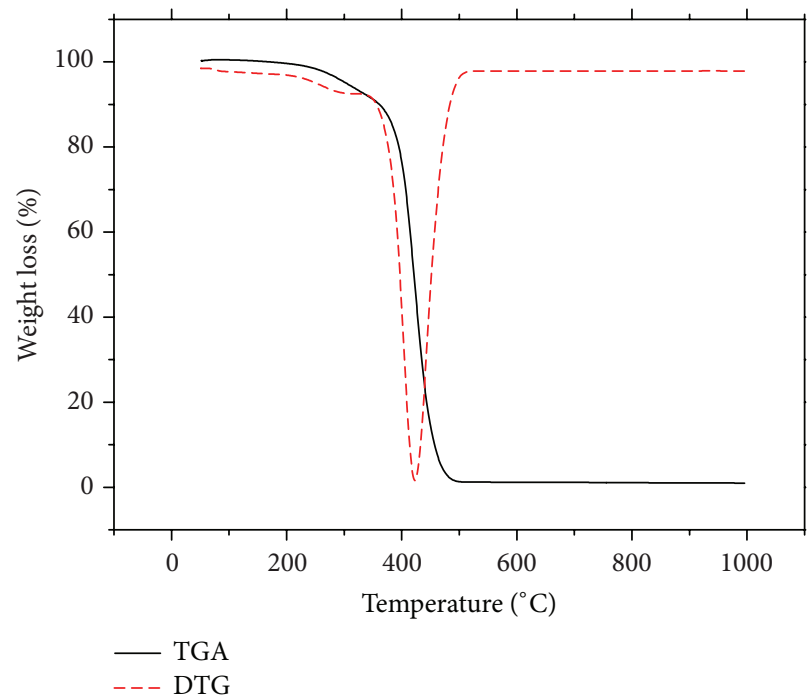

(b)

FIGURE 5: TGA and DTG curves of weight loss of Nigella sativa oil: (a) supercritical fluid 540 and (b) cold press.

as a function of heating is recorded. The TGA and the DTG curves revealed an inverse linear correlation between the weight and the temperature as the NSO lost weight with an increase in the temperature. From TGA profile of both oils, there is no weight loss observed before $200^{\circ} \mathrm{C}$. TGA and DTG curves' behavior remained similar for the CP oil which showed similar thermal behavior with SFE oil. This might be due to moisture evaporation and the presence of other volatiles in oil samples. The onset temperature and peak value of the SFE oil compared to CP oil are also similar. Thus, it is clear that the thermal stability of the $N$. sativa seed oils was not significantly affected by the type of extraction method.

\section{Conclusion}

In conclusion, the NSO extracted by using supercritical fluid had a high concentration of thymoquinone and total phenolic compounds. Moreover, the antioxidant activities were high with low $\mathrm{IC}_{50}$ value as established by DPPH and FRAP assays. The oil extracted by CP and SFE had no significant differences in their thermal profiles with no weight loss observed before $200^{\circ} \mathrm{C}$ and both oils have the same functional groups. The GC-MS showed significant differences in the two oil profiles which are directly affected by the extraction method employed. The SFE method can be considered as the 
optimum process for the extraction of NSO since the method enhances the quality of the yield in comparison with $\mathrm{CP}$.

\section{Competing Interests}

The authors declare no conflict of interests of any kind.

\section{Acknowledgments}

This research was supported by Universiti Putra Malaysia grant (GP-IPS/2014/9438743).

\section{References}

[1] M. Burits and F. Bucar, "Antioxidant activity of Nigella sativa essential oil," Phytotherapy Research, vol. 14, no. 5, pp. 323-328, 2000.

[2] M. A. Randhawa and M. S. Alghamdi, "Anticancer activity of Nigella sativa (Black Seed) - a review," American Journal of Chinese Medicine, vol. 39, no. 6, pp. 1075-1091, 2011.

[3] A. Piras, A. Rosa, B. Marongiu et al., "Chemical composition and in vitro bioactivity of the volatile and fixed oils of Nigella sativa L. extracted by supercritical carbon dioxide," Industrial Crops and Products, vol. 46, pp. 317-323, 2013.

[4] M. F. Ramadan, "Nutritional value, functional properties and nutraceutical applications of black cumin (Nigella sativa L.): an overview," International Journal of Food Science and Technology, vol. 42, no. 10, pp. 1208-1218, 2007.

[5] M. F. Ramadan, L. W. Kroh, and J.-T. Mörsel, "Radical scavenging activity of black cumin (Nigella sativa L.), coriander (Coriandrum sativum L.), and Niger (Guizotia abyssinica Cass.) crude seed oils and oil fractions," Journal of Agricultural and Food Chemistry, vol. 51, no. 24, pp. 6961-6969, 2003.

[6] M. K. A. Sahak, N. Kabir, G. Abbas, S. Draman, N. H. Hashim, and D. S. Hasan Adli, "The role of Nigella sativa and its active constituents in learning and memory," Evidence-Based Complementary and Alternative Medicine, vol. 2016, Article ID 6075679, 6 pages, 2016.

[7] C. C. Woo, A. P. Kumar, G. Sethi, and K. H. B. Tan, "Thymoquinone: potential cure for inflammatory disorders and cancer," Biochemical Pharmacology, vol. 83, no. 4, pp. 443-451, 2012.

[8] J. Pokorný and J. Korczak, "Preparation of natural antioxidant," in Antioxidants in Food: Practical Applications, chapter 13, CRC Press, 2001.

[9] M. Kiralan, G. Özkan, A. Bayrak, and M. F. Ramadan, "Physicochemical properties and stability of black cumin (Nigella sativa) seed oil as affected by different extraction methods," Industrial Crops and Products, vol. 57, pp. 52-58, 2014.

[10] C. Soto, R. Chamy, and M. E. Zúñiga, "Enzymatic hydrolysis and pressing conditions effect on borage oil extraction by cold pressing," Food Chemistry, vol. 102, no. 3, pp. 834-840, 2007.

[11] M. E. Zúñiga, C. Soto, A. Mora, R. Chamy, and J. M. Lema, "Enzymic pre-treatment of Guevina avellana mol oil extraction by pressing," Process Biochemistry, vol. 39, no. 1, pp. 51-57, 2003.

[12] M. J. H. Akanda, M. Z. I. Sarker, S. Ferdosh, M. Y. A. Manap, N. N. N. A. Rahman, and M. O. A. Kadir, "Applications of supercritical fluid extraction (SFE) of palm oil and oil from natural sources," Molecules, vol. 17, no. 2, pp. 1764-1794, 2012.

[13] Z. Solati, B. S. Baharin, and H. Bagheri, "Antioxidant property, thymoquinone content and chemical characteristics of different extracts from Nigella sativa L. seeds," Journal of the American Oil Chemists' Society, vol. 91, no. 2, pp. 295-300, 2014.

[14] S. Cheikh-Rouhou, S. Besbes, B. Hentati, C. Blecker, C. Deroanne, and H. Attia, "Nigella sativa L.: chemical composition and physicochemical characteristics of lipid fraction," Food Chemistry, vol. 101, no. 2, pp. 673-681, 2007.

[15] M. B. Atta, "Some characteristics of nigella (Nigella sativa L.) seed cultivated in Egypt and its lipid profile," Food Chemistry, vol. 83, no. 1, pp. 63-68, 2003.

[16] A. Khoddami, H. M. Ghazali, A. Yassoralipour, Y. Ramakrishnan, and A. Ganjloo, "Physicochemical characteristics of Nigella seed (Nigella sativa L.) oil as affected by different extraction methods," Journal of the American Oil Chemists' Society, vol. 88, no. 4, pp. 533-540, 2011.

[17] AOAC International, Official Methods of Analysis of AOAC International, AOAC International, 2005.

[18] M. Ismail, G. Al-Naqeep, and K. W. Chan, "Nigella sativa thymoquinone-rich fraction greatly improves plasma antioxidant capacity and expression of antioxidant genes in hypercholesterolemic rats," Free Radical Biology and Medicine, vol. 48, no. 5, pp. 664-672, 2010.

[19] O. A. Ghosheh, A. A. Houdi, and P. A. Crooks, "High performance liquid chromatographic analysis of the pharmacologically active quinones and related compounds in the oil of the black seed (Nigella sativa L.)," Journal of Pharmaceutical and Biomedical Analysis, vol. 19, no. 5, pp. 757-762, 1999.

[20] M. S. Blois, "Antioxidant determinations by the use of a stable free radical," Nature, vol. 181, no. 4617, pp. 1199-1200, 1958.

[21] I. F. F. Benzie and J. J. Strain, "Ferric reducing/antioxidant power assay: direct measure of total antioxidant activity of biological fluids and modified version for simultaneous measurement of total antioxidant power and ascorbic acid concentration," Methods in Enzymology, vol. 299, pp. 15-27, 1999.

[22] V. L. Singleton, R. Orthofer, and R. M. Lamuela-Raventós, “[14] Analysis of total phenols and other oxidation substrates and antioxidants by means of folin-ciocalteu reagent," Methods in Enzymology, vol. 299, pp. 152-178, 1999.

[23] Z. Solati, B. S. Baharin, and H. Bagheri, "Supercritical carbon dioxide (SC-CO2) extraction of Nigella sativa L. oil using full factorial design," Industrial Crops and Products, vol. 36, no. 1, pp. 519-523, 2012.

[24] S. Stein, D. Mirokhin, D. Tchekhovskoi et al., The NIST Mass Spectral Search Program for the NIST/EPA/NIH Mass Spectra Library, Standard Reference Data Program of the National Institute of Standards and Technology, Gaithersburg, Md,USA, 2002.

[25] R. P. Adams, Identification of Essential Oil Components by Gas Chromatography/Mass Spectrometry, Allured Publishing Corporation, 2007.

[26] V. Y. Ixtaina, A. Vega, S. M. Nolasco et al., "Supercritical carbon dioxide extraction of oil from Mexican chia seed (Salvia hispanica L.): characterization and process optimization," The Journal of Supercritical Fluids, vol. 55, no. 1, pp. 192-199, 2010.

[27] H. Lutterodt, M. Luther, M. Slavin et al., "Fatty acid profile, thymoquinone content, oxidative stability, and antioxidant properties of cold-pressed black cumin seed oils," LWT-Food Science and Technology, vol. 43, no. 9, pp. 1409-1413, 2010.

[28] E. Daukšas, P. R. Venskutonis, V. Povilaityte, and B. Sivik, "Rapid screening of antioxidant activity of sage (Salvia officinalis L.) extracts obtained by supercritical carbon dioxide at different extraction conditions," Nahrung/Food, vol. 45, no. 5, pp. 338-341, 2001. 
[29] M. Oktay, İ. Gülçin, and Ö. İ. Küfrevioğlu, "Determination of in vitro antioxidant activity of fennel (Foeniculum vulgare) seed extracts," LWT_Food Science and Technology, vol. 36, no. 2, pp. 263-271, 2003.

[30] M. Sielicka and U. Samotyja, "Solvent influence on antioxidant activity assay of selected cold-pressed plant oils," PhD Interdisciplinary Journal, vol. 1, pp. 67-74, 2013.

[31] A. Ghasemzadeh, H. Z. E. Jaafar, and A. Rahmat, "Antioxidant activities, total phenolics and flavonoids content in two varieties of malaysia young ginger (Zingiber officinale Roscoe)," Molecules, vol. 15, no. 6, pp. 4324-4333, 2010.

[32] M. Viuda-Martos, M. A. Mohamady, J. Fernández-López et al., "In vitro antioxidant and antibacterial activities of essentials oils obtained from Egyptian aromatic plants," Food Control, vol. 22, no. 11, pp. 1715-1722, 2011.

[33] H. Gloria and J. M. Aguilera, "Assessment of the quality of heated oils by differential scanning calorimetry," Journal of Agricultural and Food Chemistry, vol. 46, no. 4, pp. 1363-1368, 1998. 


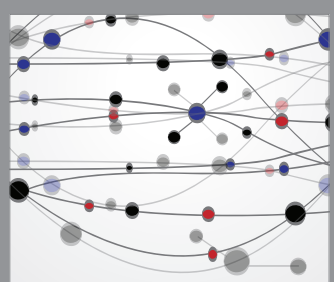

The Scientific World Journal
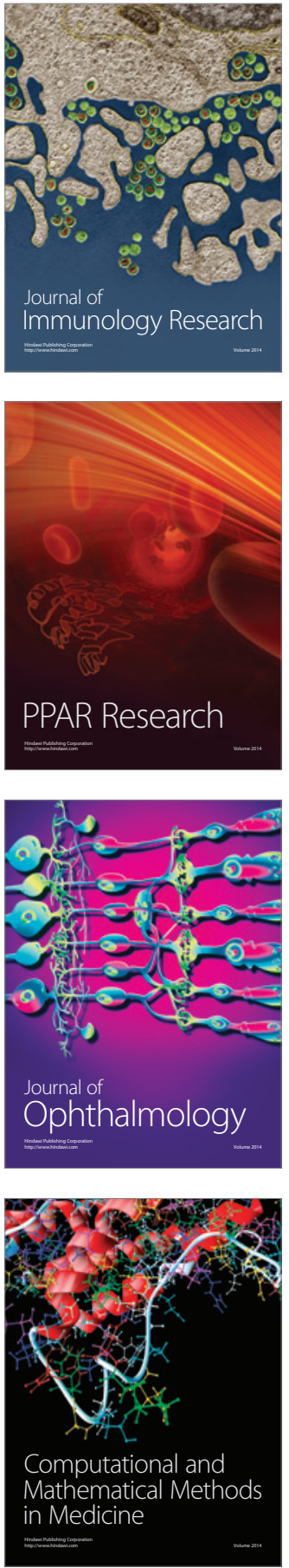

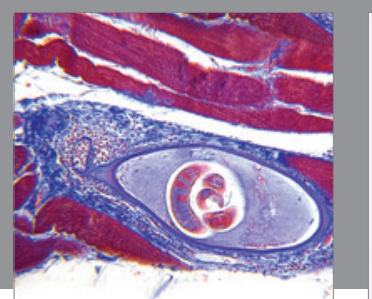

Gastroenterology Research and Practice

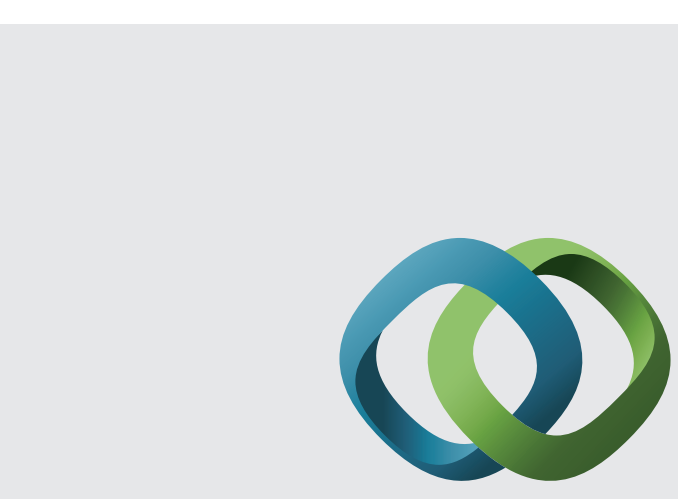

\section{Hindawi}

Submit your manuscripts at

http://www.hindawi.com
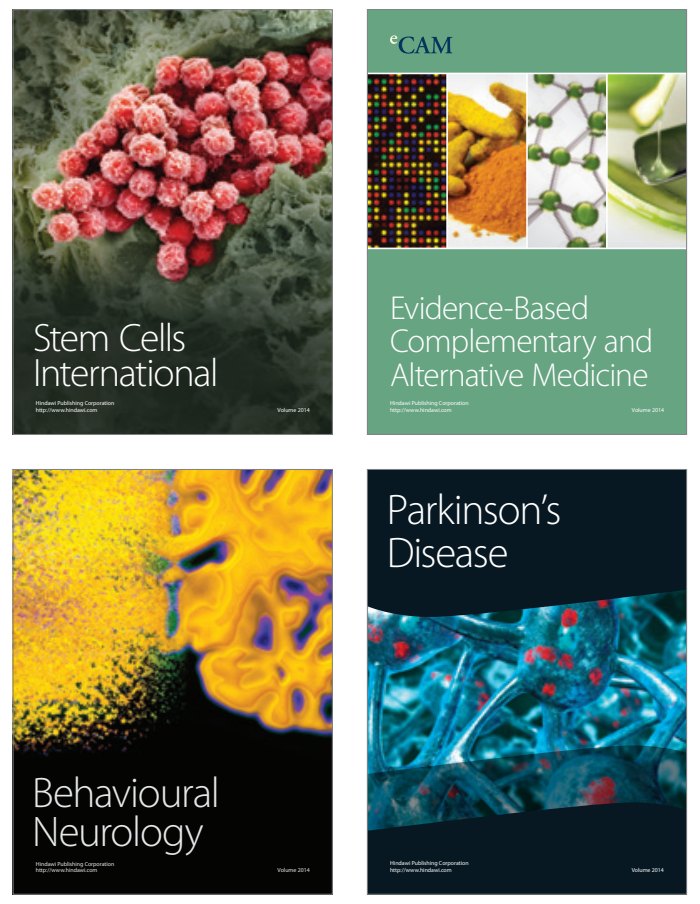
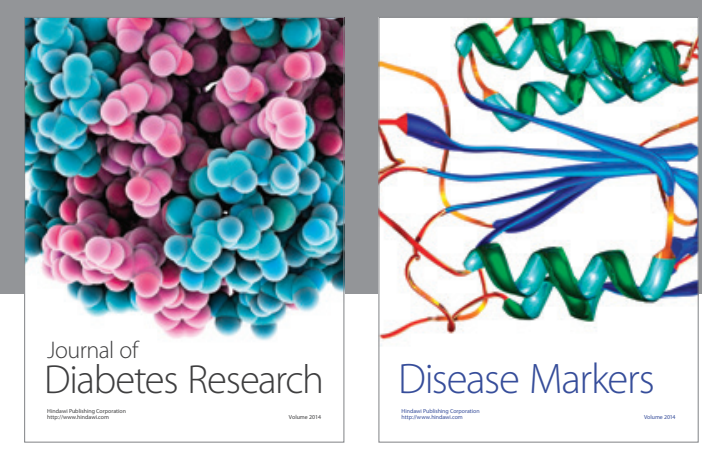

Disease Markers
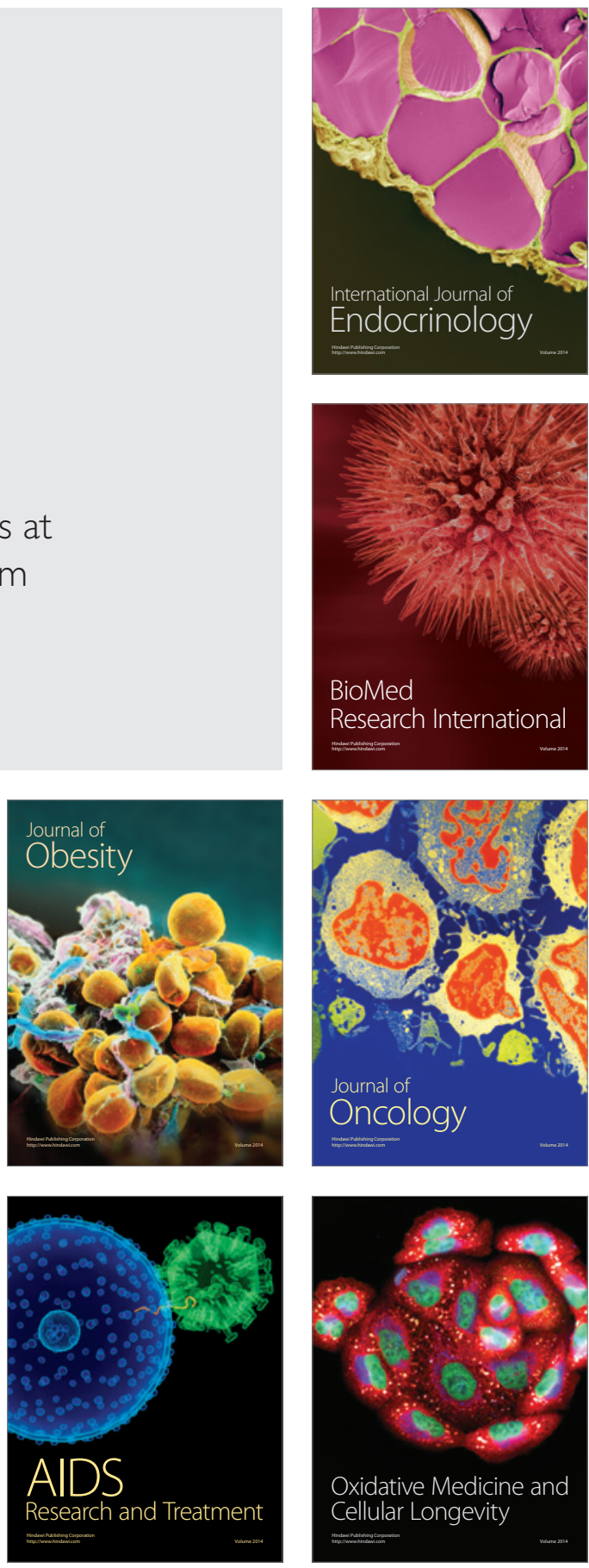